\title{
The Analysis of Heat Affected Zone Width of Vehicle Wheel Rim Flash Butt Welding
}

\author{
WANG Haibao, YANG Zisen, LV Yanchun, MA Changwen, WANG Weihua \\ ${ }^{1}$ Shougang Research Institute of Technology, Beijing, 100043 \\ ${ }^{2}$ Beijing Key Laboratory of Green Recyclable Process for Iron \& steel Production Technology, Beijing, 100043 \\ ${ }^{3}$ Beijing Engineering Research Center of Energy Steel, Beijing, 100043
}

\begin{abstract}
The FEM model of temperature field was built using FEM soft of ANSYS according to flash butt welding parameters: the amount of burnt 、 the time of burnt and the velocity of burnt, which come from four manufacturing vehicle wheels factories. Then the heat affected zone width of four factories was analyzed, as a result that the higher of the velocity of burnt, the narrower of the heat affected zone width, consequently, the guidance of flash butt welding parametres can be offered to manufacturing vehicle wheels factories.
\end{abstract}

\section{Introduction}

The vehicle wheel sustains vertical load, horizontal force, driving torque and the other stress during steering, the vehicle wheel was highly rotating component, so it should be high dimensional accuracy, low degree of unbalance, and the wheel rim configuration also should be accurate, which supports tires safely; and the vehicle wheel also should be high rigidity, elastic and fatigue property. The steel wheels are lower cost and more security than aluminum wheels, so the steel wheels have a lot of advantages. The steel wheels were mainly used for heavy-duty freight vehicles and low-end passenger cars.

The steel wheel rim was processed by edge rolling steel plate, butt welding and so on. As the hardness is high, and plasticity is low in heat affected zone when the vehicle wheel rim was welding, as a result that the cracks were often found in the flaring process, then the cracks can be reduced by narrowing down heat affected zone through controlling technological parameters. This paper mainly analyzes influence of different weld technological parameters from four manufacturing vehicle wheels factories on the heat affected zone, by using FEM calculation and simulation.

\section{Fundamental equation}

In this section, the $\mathrm{r}, \mathrm{z}$ are respectively radial direction coordinate and axial direction coordinate; the $\mathrm{U}$ represents voltage, $\rho_{E}$ represents electrical resistance of material; $\mathrm{T}$ represents temperature; $\mathrm{C}$ represents heat capacity of material; $\rho$ represents density, $\mathrm{k}$ represents heat conductivity coefficient, which changes with temperature; ${ }^{\rho_{e}}$ represents electrical resistance, $\triangle \mathrm{U}$ represents voltage drop of contact surface; $R_{C}$ represents surface contact electrical resistance; $\mathrm{K}$ represents coefficient of steel nature, 1 was chosen in this paper; $\mathrm{S}$ represents sectional area of weld assembly;

$v_{f}$ represents welding speed; J represents electric current density.

The fundamental equations of coupling calculation of heat and electricity during wheel rim welding includes electric potential equations which describe voltage distribution, and heat conduction equations which describe heat production, heat dissipation and distribution of temperature.

According to electromagnetic field theory, the electric field distribution satisfies Laplace equation when electric potential was taken. For the problem of axial symmetry, the law of voltage distribution in the body can be described by the following differential equation: ${ }^{[1]}$

$$
\frac{\partial}{\partial r}\left(\frac{1}{\rho_{E}} \frac{\partial U}{\partial r}\right)+\frac{1}{\rho \cdot r} \frac{\partial U}{\partial r}+\frac{\partial}{\partial z}\left(\frac{1}{\rho_{E}} \frac{\partial U}{\partial z}\right)=0
$$

Along with the increase of welding time, the resistivity of the material changes with the temperature, and the voltage distribution is a transient process. The contact surface satisfies this equation: $J=\Delta U / \rho c$.

The resistance flash butt welding belongs to typical issue of transient heat transmission with internal heat source. In condition of axial symmetry, the heat differential equation can be described by the heat differential equation with internal heat source ${ }^{[2]}$.

$$
\rho c \frac{\partial T}{\partial t}=\frac{\partial}{\partial r}\left(k \frac{\partial T}{\partial r}\right)+\frac{k}{r} \frac{\partial T}{\partial r}+\frac{\partial}{\partial z}\left(k \frac{\partial T}{\partial z}\right)+q_{v}
$$


The heat source intensity q of each element can be worked out by analysis on electric potential distribution using FEM.

$$
q_{v}=\left[\left(\frac{\partial U}{\partial r}\right)^{2}+\left(\frac{\partial U}{\partial z}\right)^{2}\right] / \rho_{e}
$$

The transient heat production on the end face of flash can be expressed as follows:

$$
Q_{c}=(\Delta U)^{2} / R_{c}+q_{v} \text { (4) }
$$

$\mathrm{R}_{\mathrm{C}}$ has a significance importance on the heating of weld assembly, which producing heat takes $85 \%-90 \%$ of the total heat, during the flash from beginning to end. As the rules of contact resistance change are complicated, the simulation will be difficult. According to the relationship between contact resistance and flash speed and the weld cross section, the weld contact resistance can be calculated by equation ${ }^{[3]}(5)$ :

$$
R_{c}=\frac{9500 K}{S^{2 / 3} v_{f}^{1 / 3} J} \cdot 10^{-6}
$$

\section{Model established}

In this paper, a total of four working conditions are simulated, and technological parameters are as follow as the table 1:

Table1. The flash butt welding parameters of four factories

\begin{tabular}{|c|c|c|c|c|}
\hline manufacturers & I & II & III & IV \\
\hline Burnt length/mm & 18 & 20 & 15 & 16 \\
\hline Burnt time/s & 13 & 18.2 & 16 & 13.8 \\
\hline Burnt velecity/mm/s & $\begin{array}{c}1.38 \\
5\end{array}$ & $\begin{array}{c}1.09 \\
9\end{array}$ & 0.9375 & 1.1594 \\
\hline
\end{tabular}

The wheel rim uses wheel steel of $6.75 \mathrm{~mm}$ thickness, and the grade of the wheel steel is 380CL. According to symmetry, one half of the weld assembly temperature was simulated in order to simplify calculation, and the models of geometry and FEM were established as follows: $6.75 \times 20 \times 42 \mathrm{~mm}$. The models can be showed in Fig1-2:

\section{Centre}

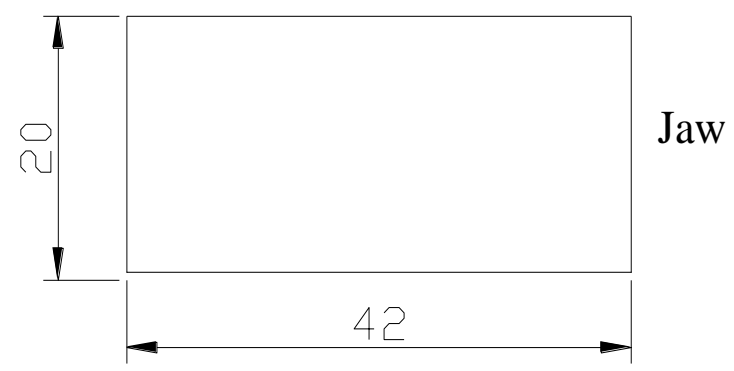

Figure1. The plan sketch of model

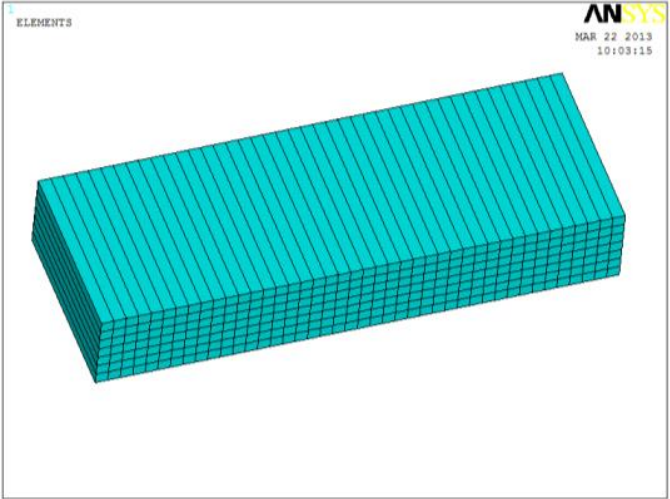

Figure2. The FEM model

\section{Boundary conditions}

The main boundary conditions are as follows:

a. The initial temperature is set to room temperature;

b. The contact between electrode and wheel steel is thermal conductivity type;

c. The composite coefficient of heat transfer was taken as radiation heat transfer and convection current between outer surface of wheel steel plate and air;

d. The other side of the flash end face of wheel steel plate is thermal free boundary;

e. The whole analysis process was divided into 10 steps according to practical the velocity of burnt, and each step burns $1.0 \mathrm{~mm}$. According to practical record weld time, the flash layer will be killed when the time out. Each calculation step size is an element length which is $1 \mathrm{~mm}$, and each step time will be determined by burnt time of every operating condition, meanwhile, the heat conductivity coefficient, specific heat, density and coefficient of heat transfer should be adjusted during calculation.

The heat source during the wheel rim flash weld can be simplified as $1500^{\circ} \mathrm{C}$ thermal load, meanwhile, the heat source is moving at speed of burnt, when the temperature of element is $1500^{\circ} \mathrm{C}$, the element will be handled, so it will not calculate anymore. As jaw site was cooled by water, so the load of jaw site is simplified to $20^{\circ} \mathrm{C}$ constant temperature load in this paper.

\section{Result analysis}

The heat affected zone of low-carbon steel can be divided into overheated zone, normalizing zone and partly phase transformation according to the region where the metallographic structure and mechanical property change, caused by high temperature heated of welding line area. The grain is bulky, and overheating metallographic structure was found in the overheated zone where was heated above $1100{ }^{\circ} \mathrm{C}$. Because the plasticity and toughness decrease in the overheated zone, so the mechanical property is quite poor in the heat affected zone. 


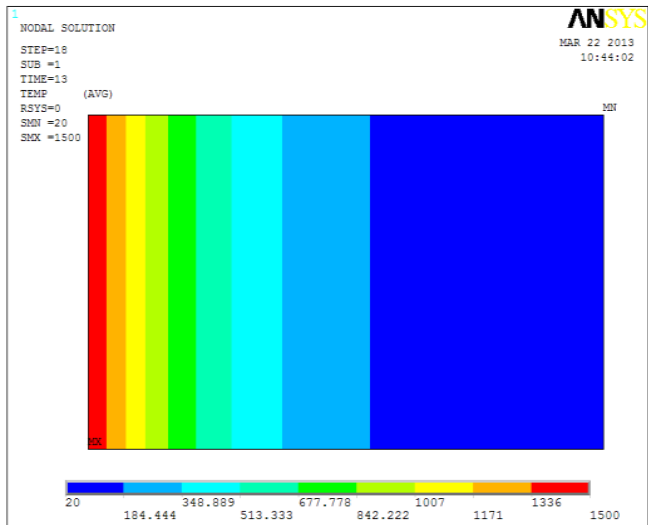

Figure3. The temperature field distribution at the end of the I

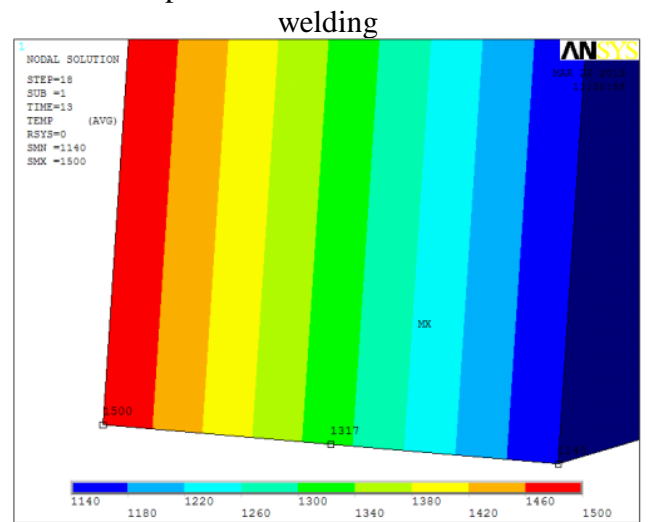

Figure4. The temperature field distribution at the end of the I welding

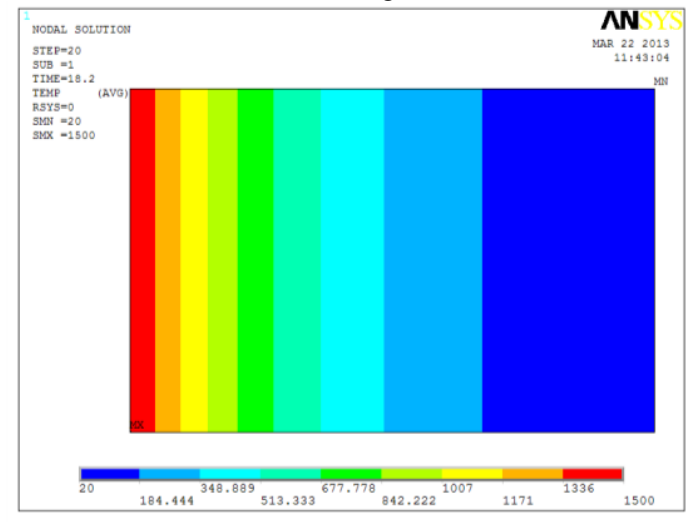

Figure5. The temperature field distribution at the end of the II

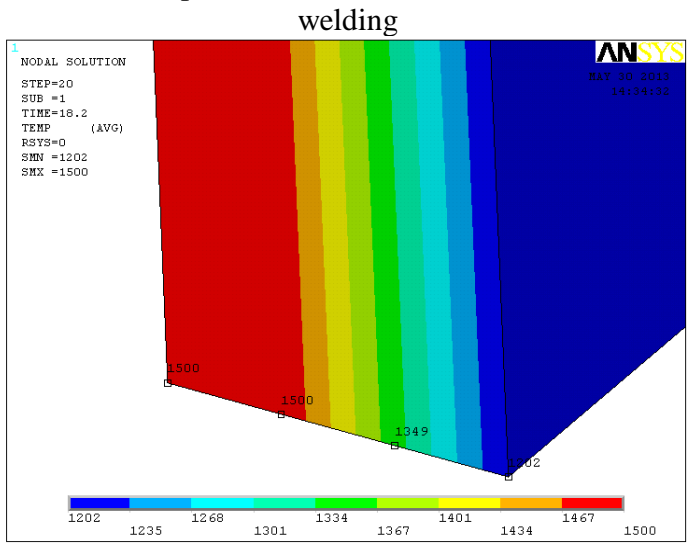

Figure6. The temperature field distribution at the end of the II welding

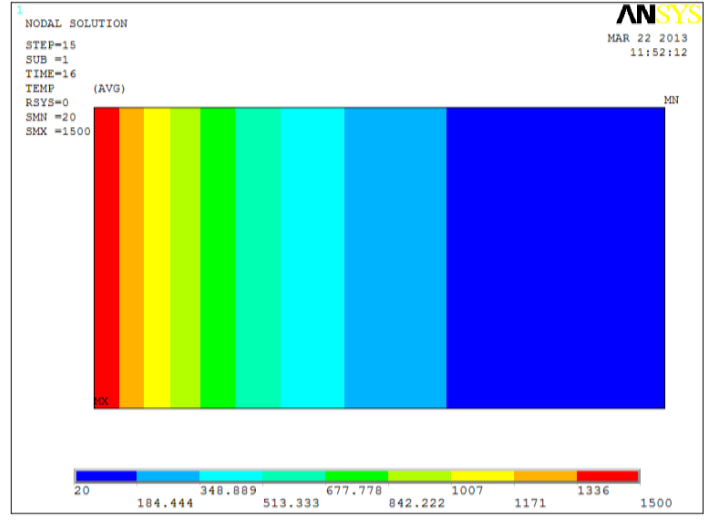

Figure7. The temperature field distribution at the end of the III welding

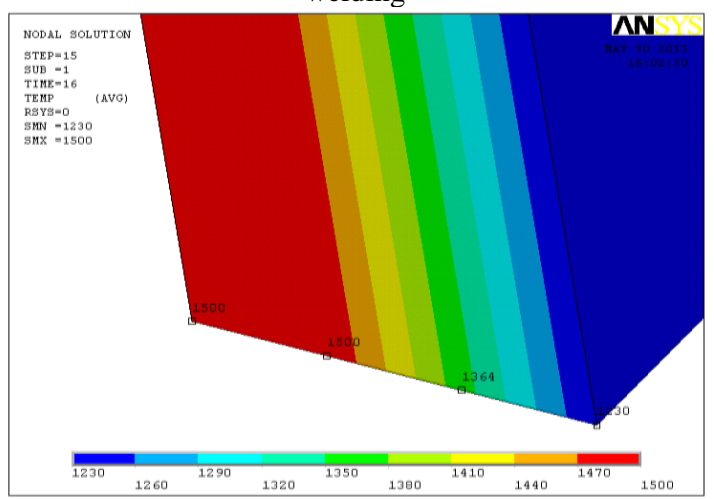

Figure8. The temperature field distribution at the end of the III welding

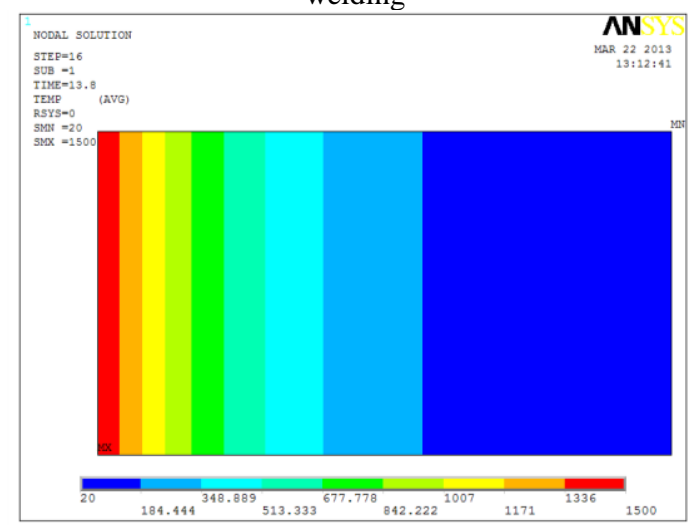

Figure9. The temperature field distribution at the end of the IV welding

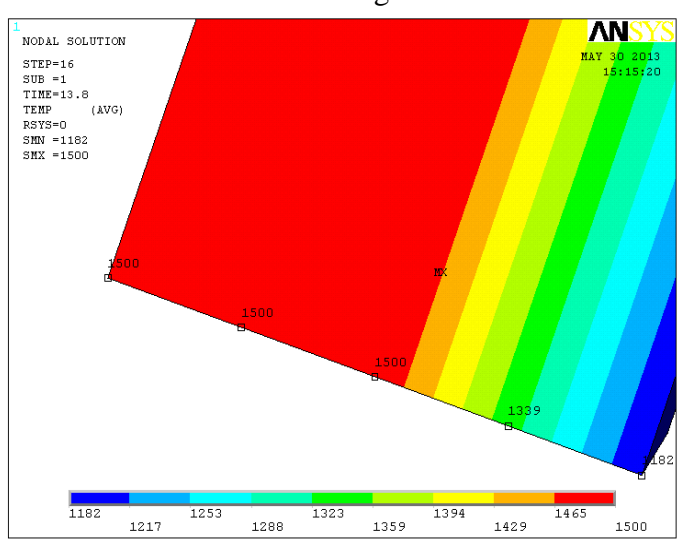

Figure10. The temperature field distribution at the end of the IV welding 
According to the calculation results of four operation conditions, the relation between the width of heat affected zone and the burnt speed was found, and the relation can be described as curve as follows.

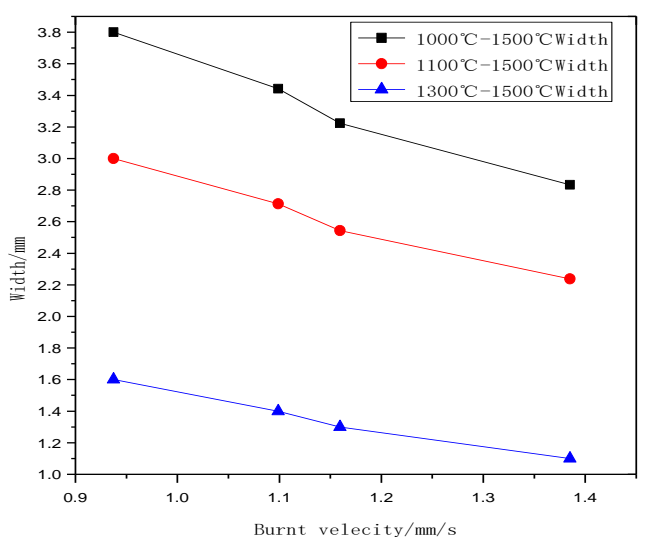

Figure11. The relation curve between the heat affected zone width and the burnt speed

Table.2 The calculating results of different welding parameters of four factories

\begin{tabular}{c|c|c|c|c}
\hline Temperature $/{ }^{\circ} \mathrm{C}$ & $\begin{array}{c}\mathrm{I} \\
/ \mathrm{mm}\end{array}$ & $\mathrm{II} / \mathrm{mm}$ & $\begin{array}{c}\mathrm{III} \\
/ \mathrm{mm}\end{array}$ & $\mathrm{IV} / \mathrm{mm}$ \\
\hline $\begin{array}{c}1000- \\
1500 \text { Width }\end{array}$ & 3.8 & 3.442 & $\begin{array}{c}3.223 \\
7\end{array}$ & 2.834 \\
\hline $\begin{array}{c}1100-1500 \\
\text { Width }\end{array}$ & 3 & 2.7132 & 2.543 & 2.238 \\
\hline $\begin{array}{c}1300-1500 \\
\text { Width }\end{array}$ & 1.6 & 1.4 & 1.3 & 1.1 \\
\hline $\begin{array}{c}\text { Burnt speed } \\
\mathrm{mm} / \mathrm{s}\end{array}$ & $\begin{array}{c}0.937 \\
5\end{array}$ & 1.099 & $\begin{array}{c}1.159 \\
4\end{array}$ & 1.385 \\
\hline
\end{tabular}

According to fig3-7, the conclusion was obtained that the width of heat affected zone decreases with the burnt velocity increases, so the burnt velocity can be increased in order to reduce heat affected zone width and reduce cracking rate.

Since only one piece plate of steel heat affected zone width was analyzed in this paper, so the actual heat affected zone width of two welding plates is twice of the results above.

\section{Conclusion}

1) The heat affected zone width decreases with the burnt velocity increases;

2) The burnt velocity can be increased in order to reduce heat affected zone width and reduce cracking problems.

3) The heat affected zone width range of four factories is between $5.6 \mathrm{~mm}$ and $7.6 \mathrm{~mm}$.

4) This conclusion is consistent with the cracking rate of four manufacturers in actual production.

\section{References}

1. Guan Zhike, Liu li, Xu Xiaofan The FEM Temperature Simulation of Railroad Rail Flash
Welding and Detection of Actual Welding. Mechanical and Electronic, 2008(5).

2. WangWei, Zhu Liumei, The Discussion of Weld Temperature Measurement Technology. Physics Measurement,1998, (6):25-27.

3. Zhang Guozhi, HuRenxi, ChenJigang The Thermal FEM Analysis Example and Guidance Course of ANSYS10.0, China Machine Press,2007. 